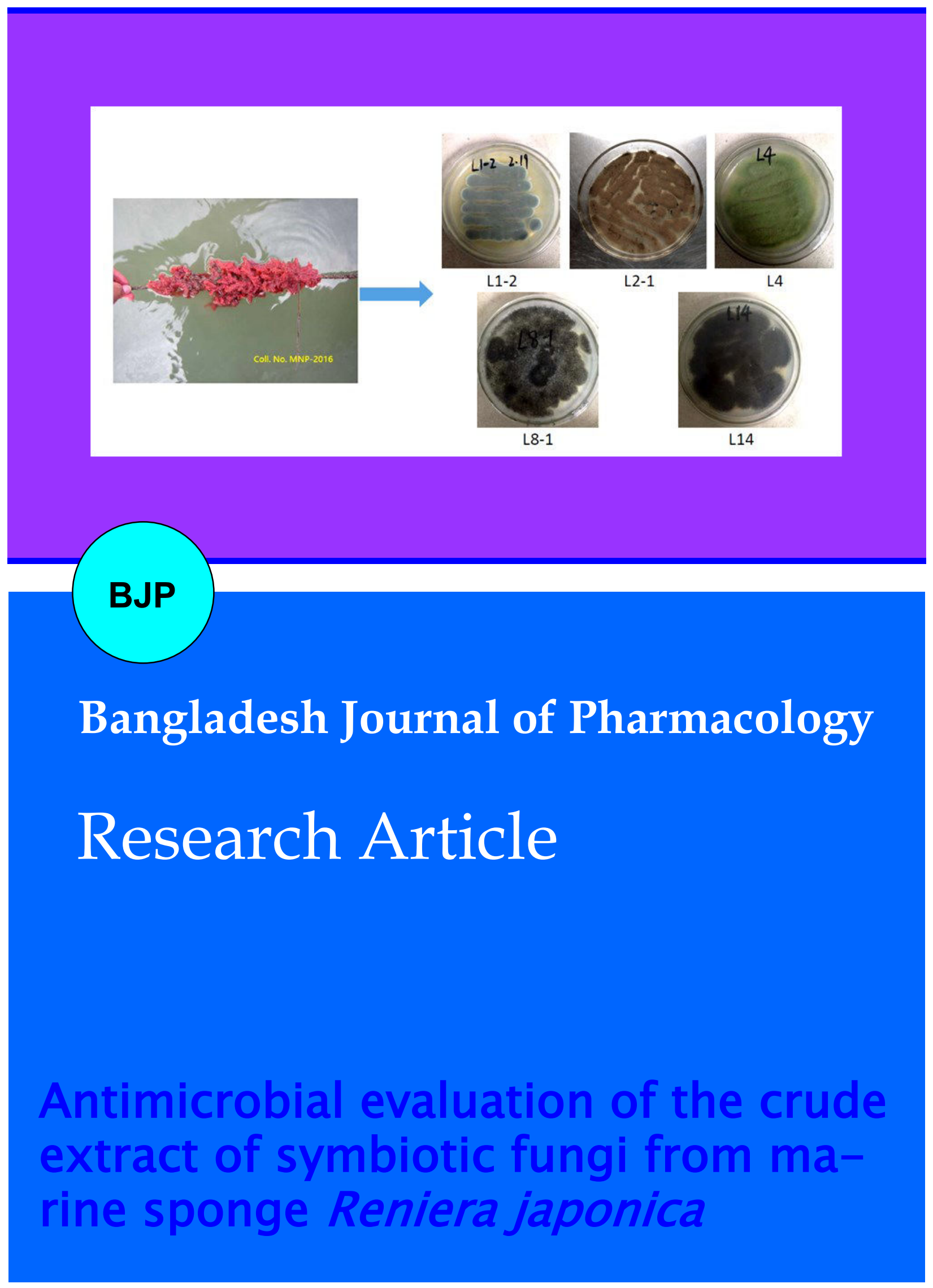


Abstracted/indexed in Academic Search Complete, Asia Journals Online, Bangladesh Journals Online, Biological Abstracts, BIOSIS Previews, CAB Abstracts, Current Abstracts, Directory of Open Access Journals, EMBASE/Excerpta Medica, Global Health, Google Scholar, HINARI (WHO), International Pharmaceutical Abstracts, Open J-gate, Science Citation Index Expanded, SCOPUS and Social Sciences Citation Index;

ISSN: $1991-0088$

\title{
Antimicrobial evaluation of the crude extract of symbiotic fungi from marine sponge Reniera japonica
}

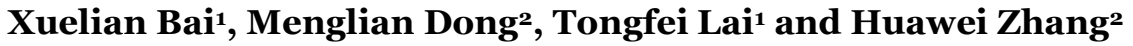 \\ ${ }^{1}$ College of Life and Environmental Sciences, Hangzhou Normal University, Hangzhou 310036, P. R. China; \\ ${ }^{2}$ School of Pharmaceutical Sciences, Zhejiang University of Technology, Hangzhou 310014, P. R. China.
}

\begin{tabular}{|c|c|}
\hline \multicolumn{2}{|l|}{ Article Info } \\
\hline Received: & 1 November 2017 \\
\hline Accepted: & 5 February 2018 \\
\hline Available Online: & 15 February 2018 \\
\hline \multicolumn{2}{|c|}{ DOI: 10.3329/bjp.v13i1.34468 } \\
\hline \multicolumn{2}{|c|}{$\begin{array}{l}\text { Cite this article: } \\
\text { Bai X, Dong M, Zhang H. Anti- } \\
\text { microbial evaluation of the crude } \\
\text { extract of symbiotic fungi from ma- } \\
\text { rine sponge Reniera japonica. Bangla- } \\
\text { desh J Pharmacol. 2018; } 13 \text { : } 53-56 \text {. }\end{array}$} \\
\hline
\end{tabular}

\begin{abstract}
Marine sponge-derived microbes are one of the rich sources of bioactive natural products with a broad spectrum of bioactivities. The present work focuses on the isolation and antimicrobial screening of the marine spongeassociated fungi from Reniera japonica MNP-2016. The results indicated that five fungi (L1-2, L2-1, L4, L8-1 and L14) were successfully isolated. Bioassay tests showed that only strain L14 had strong inhibitory effect on the pathogens, Staphyloccocus aureus, Escherichia coli and Candida albicans. 18S rDNA sequence analysis indicated that strain L14 was ascribed to Aspergillus genus. To the best of our knowledge, this work was the first report on the isolation and antimicrobial evaluation of fungi from $R$. japonica.
\end{abstract}

\section{Introduction}

Marine sponge is a rich treasure of symbiotic microorganisms, including actinomycetes, bacteria, fungi and so on (Wei et al., 2009). These microbes have potential capability to produce bioactive secondary metabolites with a broad spectrum of application in the field of medicine and agriculture (Bhatnagar et al., 2010; Zhang et al., 2017). More interestingly, marine sponge-derived fungi accounted for the largest number (33\%) of natural products and had the highest number of new compounds during the period from 2003 to 2012 (Pejin et al., 2013).

In order to seek more natural products with novel structures and/or potent biological properties for the discovery of new drug candidates, isolation and antimicrobial evaluation of fungi derived from the marine sponge Reniera japonica were firstly carried out in our laboratory. $R$. japonica, orange-colored marine sponge, is commonly found in the north China coast (Zhang et al., 2012) and the southern part of the Japanese coast (Miki et al., 1995).

\section{Materials and Methods \\ Sponge collection and classification}

The specimen of marine sponge (MNP-2016) was collected from the Xinghai Bay of Dalian city in China and classified as $R$. japonica by the Associate Professor Mingguang Mao at the Dalian Ocean University, China.

\section{Fungal strain isolation and identification}

A total of five fungal strains (coded as L1-2, L2-1, L4, L8 -1 and L14) were isolated and purified from the $R$. japonica using the method previously reported (Miki et al., 1995). All these fungal strains were transferred into the potato dextrose agar slants separately followed by storing at $4^{\circ} \mathrm{C}$. According to molecular phylogeny based on $18 \mathrm{~S}$ rDNA sequence and morphological characterization by microscope, genus of bioactive strain was classified (Corsaro et al., 2017).

Preparation of fermentation broth and ethyl acetate extract

Each strain was cultured on the potato dextrose agar at 
$30^{\circ} \mathrm{C}$ for 7 days. Then a balanced amount of fungal colony was transferred to the culture broth in $500 \mathrm{~mL}$ Erlenmeyer flask which contained $300 \mathrm{~mL}$ sterilized potato dextrose broth, followed by shaking at $200 \mathrm{rpm}$ for 7 days at $30^{\circ} \mathrm{C}$. After that, the mycelium and the fermentation broth were separated with medical absorbent gauze. The filtrate was extracted twice with 450 $\mathrm{mL}$ ethyl acetate (Merck) each Erlenmeyer flask. The upper solvent was dried by a rotary evaporator at $25^{\circ} \mathrm{C}$ in vacuum to yield the ethyl acetate extract, which possibly had antimicrobial secondary metabolites. And according to the medium whether added with salt or not, these ethyl acetate extracts of fungal strains were numbered as L1-2, L1-2J, L2-1, L2-1J, L4, L4J, L8-1, L81J, L14 and L14J (J represents salting). Each afforded extract was kept in a vacuum drier for 3 days and dissolved in dimethyl sulfoxide (Merck) in 0.1, 1 and 10 $\mathrm{mg} / \mathrm{mL}$.

\section{Antibacterial test}

Anibacterial assay was carried out using the method developed by Wang et al. (2008). Two human pathogenic bacteria, Staphyloccocus aureus and Escherichia coli, were used in the screening process. Each strain was transferred into one $250 \mathrm{~mL}$ Erlenmeyer flask which contained $150 \mathrm{~mL}$ sterilized Luria-Bertani medium and incubated at $30^{\circ} \mathrm{C}$ on a rotary shaker at $180 \mathrm{rpm}$ for 24 hours. About $10 \mathrm{~mL}$ of the melted water agar medium was poured into a petri dish $(\varphi=9 \mathrm{~cm})$ followed by lay with five Oxford cups equidistantly. $200 \mu \mathrm{L}$ of cultured bacterium was thoroughly mixed with $150 \mathrm{~mL}$ of sterilized nutrition agar at $50^{\circ} \mathrm{C}$ and immediately put on the solidified water agar medium. After cooling, Oxford cups were removed and resulted in five holes $(\varphi=6$ $\mathrm{mm}$ ) in each petri dish. Three holes were respectively added with $100 \mu \mathrm{L}$ of each sample. Two remaining holes were added with $100 \mu \mathrm{L}$ of the positive control ampicillin sodium $(0.2 \mathrm{mg} / \mathrm{mL}$, Amresco) and $100 \mu \mathrm{L}$ of negative control dimethyl sulfoxide. Then the plates were incubated at $30^{\circ} \mathrm{C}$ for 24 hours. All tests were performed in triplicate and the average value of diameters of inhibition zone $(\mathrm{mm})$ were expressed as the antibacterial activity.

\section{Antifungal test}

The antifungal assay was carried out using our previ-

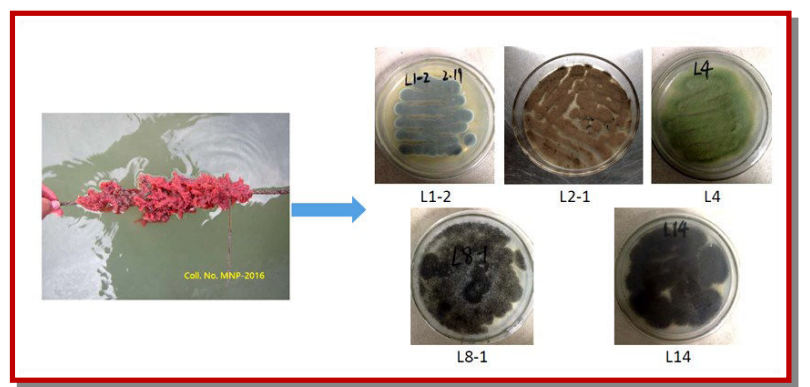

Figure 1: Five symbiotic strains from Reniera japonica MNP-2016 ous described method (Zhang et al., 2014). The human pathogenic fungus, Candida albicans, was transferred into a $250 \mathrm{~mL}$ Erlenmeyer flask which contained $150 \mathrm{~mL}$ sterilized potato dextrose broth and incubated at $30^{\circ} \mathrm{C}$ on a rotary shaker at $180 \mathrm{rpm}$ for 48 hours. During the process of prepare the testing plate, potato dextrose agar was used as the upper medium layer. The positive control was amphotericin B $(0.3 \mathrm{mg} / \mathrm{mL}$, SigmaAldrich) and each plate was incubated at $30^{\circ} \mathrm{C}$ for 48 hours. All tests were carried out in triplicate and the inhibitory effect was expressed as the average value of diameters $(\mathrm{mm})$.

\section{Results}

Five fungal strains (L1-2, L2-1, L4, L8-1 and L14) were isolated and purified from the marine sponge $R$. japonica (Figure 1). As shown in Table I, most marine sponge-derived strains had no activity against the three human pathogens, E. coli, S. aureus and C. albicans.

Only the ethyl acetate extract of fermentation broth of the strain L14 displayed a broad spectrum of antimicrobial activity and exhibited concentration-dependent manner (Figure 2). The average value of inhibition zones against $E$. coli, S. aureus and $C$. albicans were respectively $28,31,18 \mathrm{~mm}$ at $10 \mathrm{mg} / \mathrm{mL}$. When the concentration of ethyl acetate extract decreased to 1 $\mathrm{mg} / \mathrm{mL}$, the average value of inhibition zones against E. coli and C. albicans reduced to $13,12 \mathrm{~mm}$, respecttively. By a combination of $18 \mathrm{~S}$ rDNA sequence analysis and morphological characters (Figure 3), strain L14 was classified as Aspergillus sp. (NCBI GenBank: MF093522).

\section{Discussion}

Five fungal strains were characterized from the $R$. japonica and according to the medium whether added with salt or not, ten different crude extracts (L1-2, L1-2J, L2-1, L2-1J, L4, L4J, L8-1, L8-1J, L14 and L14J) were gotten. The results of anti-microbial tests indicated that different fungi or different mediums yield different crude extracts and these crude extracts showed different antimicrobial activities against three human microbial pathogens, including S. aureus, E. coli and C.

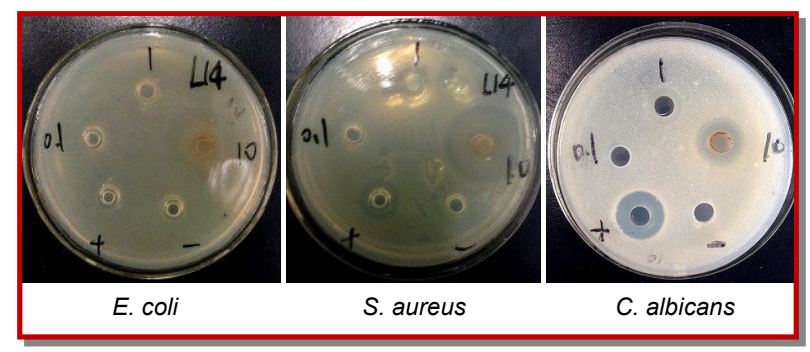

Figure 2: Antimicrobial effects of ethyl acetate extract of fungal strain L14 


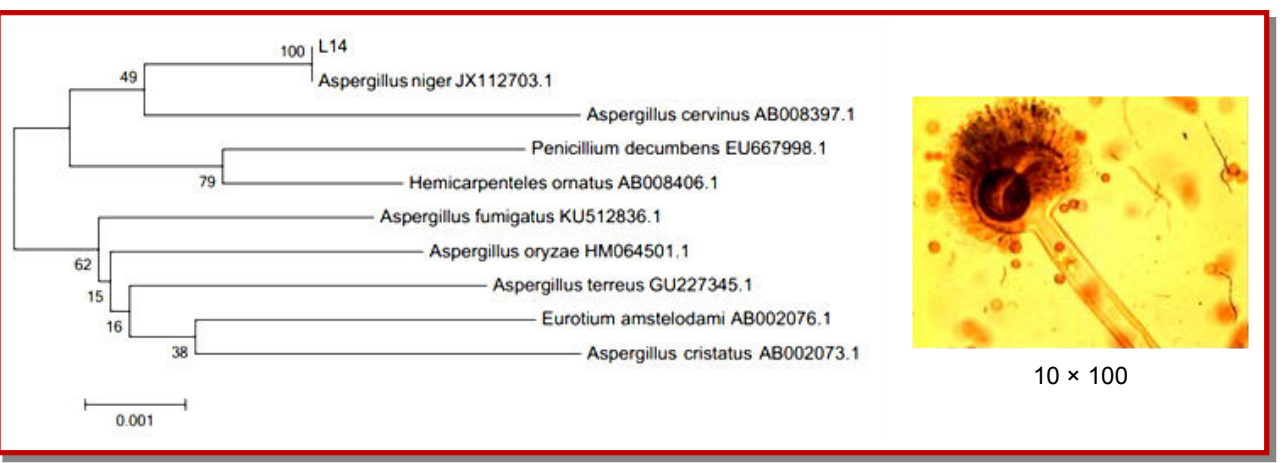

Figure 3: Molecular phylogeny and morphology of fungal strain L14

albicans. What's more, most of these crude extracts of five fungal strains from $R$. japonica were inactive against three human microbial pathogens.

As far as antibacterial activity concerned, strain L14 was the best bio-control candidate with the strong inhibitory effects on three human pathogens. Previous chemical investigation indicated that Aspergillus genus is one of rich producers of terpenes, alkaloids, peptides, aromatics with a broad spectrum of biological activities (Zhang et al., 2017). Therefore, natural products

\begin{tabular}{|c|c|c|c|c|}
\hline \multicolumn{5}{|c|}{ Table I } \\
\hline \multicolumn{5}{|c|}{ Antimicrobial effects of symbiotic fungal strains from Reniera japonica } \\
\hline \multirow[t]{2}{*}{ Strain No. } & \multirow{2}{*}{$\begin{array}{l}\text { Concentration } \\
(\mathrm{mg} / \mathrm{mL})\end{array}$} & \multicolumn{3}{|c|}{ Antifungal effects } \\
\hline & & E. coli & S. aureus & C. albicans \\
\hline \multirow[t]{3}{*}{ L1-2 } & 0.1 & - & - & - \\
\hline & 1 & - & - & - \\
\hline & 10 & - & - & - \\
\hline \multirow[t]{3}{*}{ L1-2J } & 0.1 & - & - & - \\
\hline & 1 & - & - & - \\
\hline & 10 & - & - & - \\
\hline \multirow[t]{3}{*}{ L2-1 } & 0.1 & - & - & - \\
\hline & 1 & - & - & - \\
\hline & 10 & - & - & - \\
\hline \multirow[t]{3}{*}{ L2-1J } & 0.1 & - & - & - \\
\hline & 1 & - & - & - \\
\hline & 10 & - & - & - \\
\hline \multirow[t]{3}{*}{ L4 } & 0.1 & - & - & - \\
\hline & 1 & - & - & - \\
\hline & 10 & - & - & - \\
\hline \multirow[t]{3}{*}{ L4J } & 0.1 & - & - & - \\
\hline & 1 & - & - & - \\
\hline & 10 & - & - & - \\
\hline \multirow[t]{3}{*}{ L8-1 } & 0.1 & - & - & - \\
\hline & 1 & - & - & - \\
\hline & 10 & - & - & - \\
\hline \multirow[t]{3}{*}{ L8-1J } & 0.1 & - & - & - \\
\hline & 1 & - & - & - \\
\hline & 10 & - & - & - \\
\hline \multirow[t]{3}{*}{ L14 } & 0.1 & - & - & - \\
\hline & 1 & ++ & - & ++ \\
\hline & 10 & ++++ & ++++ & +++ \\
\hline \multirow[t]{3}{*}{ L14J } & 0.1 & - & - & - \\
\hline & 1 & - & - & - \\
\hline & 10 & - & - & - \\
\hline Ampicillin sodium & 0.2 & ++++ & +++ & - \\
\hline Amphotericin B & 0.3 & - & - & ++++ \\
\hline DMSO & & - & - & - \\
\hline
\end{tabular}

aExpressed by the diameter of inhibition zones: $(-)=$ no inhibition; $(+)=<10 \mathrm{~mm} ;(++)=10-15 \mathrm{~mm} ;\left(^{+++}\right)=16-20 \mathrm{~mm} ;(++++)=>20 \mathrm{~mm}$ 
chemistry study of strain L14 need be carried out in near further.

\section{Conflict of Interest}

All authors declare no conflict of interest.

\section{Acknowledgement}

Financial support from the National Natural Science Foundation of China (No. 41776139), the Zhejiang Natural Science Foundation of China (LY16H300007), the Hangzhou Science and Technology Planning Project (20170432B02) and the TriFive Cultivating Project (2016XJSGWXM26) and the Laboratory Opening Project (SYSKF2017007) from Hangzhou Normal University are greatly appreciated.

\section{References}

Bhatnagar I, Kim SK. Immense essence of excellence: Marine microbial bioactive compounds. Mar Drugs. 2010; 8: 2673701.

Corsaro D, Kohsler M, Filippo MMD, Venditti D, Monno R, Cave DD, Berrilli F, Walochnik J. Update on Acanthamoeba jacobsi genotype T15, including full-length $18 \mathrm{~S}$ rDNA molecular phylogeny. Parasitol Res. 2017; 116: 1273-84.

Huang Y, Li ZY. Chemical defense and active compounds of sponge and sponge-associated microorganisms. Biotechnol Bull. 2006; 25: 13-17.

Jin LM, Quan CS, Hou XY, Fan SD. Potential pharmacological resources: Natural bioactive compounds from marinederived fungi. Mar Drugs. 2016; 14: ID76.
Miki W, Otaki N, Yokoyama A, Kusumi T. Possible origin of zeaxanthin in the marine sponge, Reniera japonica. Experientia 1995; 52: 93-96.

Pejin B, Jovanovic KK, Mojovic M, Savic AG. New and highly potent antitumor natural products from marine-derived fungi: Covering the period from 2003 to 2012. Curr Top Med Chem. 2013; 13: 2745-66.

Wang CT, Cao YP, Sun BG, Liu XD, Zhang H. Screening of bacteriocin-like substance producing lactic acid bacterium and its characteristics. Chn Brw. 2008; 27: 50-53.

Wang CY, Wang KL, Qian PY, Xu Y, Chen M, Zheng JJ, Liu M, Shao CL, Wang CY. Antifouling phenyl ethers and other compounds from the invertebrates and their symbiotic fungi collected from the South China Sea. AMB Expr. 2016; 6: 2-10.

Wei RB, Li FC, Song R, Qin S. Comparison of two marine sponge-associated penicillium strains DQ25 and SC10: Differences in secondary metabolites and their bioactivities. Ann Microbio. 2009; 59: 579-85.

Zhang Y, Jun M, Feng Y, Li HN, Dong XW. Biological and chemical diversity of cytotoxin-producing symbiotic marine fungi in intertidal zone of Dalian. Chin Sci Bull. 2012; 58: 2290-97.

Zhang Y, Mu J, Feng Y, Kang Y, Zhang J, Gu PJ, Wang Y, Ma LF, Zhu YH. Broad-spectrum antimicrobial epiphytic and endophytic fungi from marine organisms: Isolation, bioassay and taxonomy. Mar Drugs. 2009; 7: 97-112.

Zhang HW, Ying C, Tang YF. Antimicrobial screening of endophytic fungi from Hypericum perforatum Linn. Pakistan J Pharm Sci. 2014; 27: 1153-56.

Zhang HW, Zhao ZP, Wang H. Cytotoxic natural products from marine sponge-derived microorganisms. Mar Drugs. 2017; 15: ID68.

\section{Author Info \\ Huawei Zhang (Principal contact) \\ । e-mail: hwzhang@zjut.edu.cn}

